\title{
WPS4353
}

\author{
Policy Research Working Paper 4353
}

\section{The Long-run Impact of Orphanhood}

\author{
Kathleen Beegle \\ Joachim De Weerdt \\ Stefan Dercon
}

The World Bank

Development Research Group

Poverty Team

September 2007 
Policy Research Working Paper 4353

\begin{abstract}
This paper presents unique evidence that orphanhood matters in the long run for health and education outcomes, in a region of Northwestern Tanzania. The paper studies a sample of 718 non-orphaned children surveyed in 1991-94, who were traced and re-interviewed as adults in 2004. A large proportion, 19 percent, lost one or more parents before the age of 15 in this period, allowing the authors to assess the permanent health and education impacts of orphanhood. The analysis

controls for a wide range of child and adult characteristics before orphanhood, as well as community fixed effects. The findings show that maternal orphanhood has a permanent adverse impact of $2 \mathrm{~cm}$ of final height attainment and one year of educational attainment. Expressing welfare in terms of consumption expenditure, the result is a gap of 8.5 percent compared with similar children whose mother survived till at least their 15 th birthday.
\end{abstract}

This paper-a product of the Poverty Team, Development Research Group-is part of a larger effort in the department to study the socio-economic impact of health shocks in low income countries. Policy Research Working Papers are also posted on the Web at http://econ.worldbank.org. The author may be contacted at kbeegle@worldbank.org.

The Policy Research Working Paper Series disseminates the findings of work in progress to encourage the exchange of ideas about development issues. An objective of the series is to get the findings out quickly, even if the presentations are less than fully polished. The papers carry the names of the authors and should be cited accordingly. The findings, interpretations, and conclusions expressed in this paper are entirely those of the authors. They do not necessarily represent the views of the International Bank for Reconstruction and Development/World Bank and its affiliated organizations, or those of the Executive Directors of the World Bank or the governments they represent. 


\title{
The Long-run Impact of Orphanhood ${ }^{1}$
}

\author{
Kathleen Beegle \\ The World Bank \\ Joachim De Weerdt \\ E.D.I., Tanzania \\ Stefan Dercon \\ Oxford University
}

Keywords: HIV-AIDS, orphans, health, education, panel data

JEL-codes: O15, I10, I20, I31

\footnotetext{
${ }^{1}$ This analysis was supported by the Trust Fund for Environmentally \& Socially Sustainable Development at the World Bank and the Economic and Social Research Council, United Kingdom. The views expressed here do not necessarily reflect those of the World Bank or its member countries. We thank John Cockburn and seminar participants at the AAEA annual meetings 2006, Child Health in Developing Countries Workshop (Bristol, UK), IFPRI, IUSSP seminar on HIV/AIDS and Poverty, Mini-conference on Development at the University of Laval, Oxford University Development Economics Conference, PAA annual meetings 2005, Research and Analysis Working Group (Dar es Salaam), and the World Bank for very useful comments. Please address correspondence to kbeegle@worldbank.org.
} 


\section{Introduction}

Childhood orphanhood is considered a major risk factor for poverty in adulthood, through, among other channels, shortfalls in human capital investments in children. This paper provides unique evidence on the long-term impact of orphanhood in a region of Tanzania near Lake Victoria, an area ravaged by HIV/AIDS. The underlying data set is a 13-year panel data set in which individuals interviewed at baseline were traced irrespective of their current residence. This allows us to focus on non-orphaned children experiencing the loss of one or both parents during the survey period, controlling for their characteristics before becoming an orphan. Furthermore, we can focus on the permanent impact in terms of height and educational attainment once these children reach adulthood and recovery is hardly possible anymore. Using within-sample estimates of the returns to height and education, we can also estimate the resulting life-time welfare loss.

We find significant permanent education and health effects. Adults who had been maternally orphaned between the ages of 7 and 15 experience a loss of, on average, nearly $2 \mathrm{~cm}$ of final attained height and one year of schooling. In contrast, paternal orphans have significantly lower height and years of schooling but our analysis shows that a causal link does not seem to exist. Our projections suggest that maternal orphanhood creates a life long deficit in consumption expenditure of roughly 8.5 percent.

In Sub-Saharan Africa, the prevalence of orphanhood among children has been greatly exacerbated by the HIV/AIDS pandemic. While there are other, more prevalent diseases in Africa, the characteristics of HIV/AIDS suggest that its economic and demographic impact will be profound. Because HIV in Africa is transmitted primarily through heterosexual contact, the epidemic is having a major effect on the mortality of men and women in their prime childbearing and earning years. With rising mortality rates and decreasing adult life expectancies, orphanhood rates in Africa continue to increase, placing increasing numbers of children at risk.

Orphanhood is expected to influence health outcomes and schooling although there are multiple potential pathways of this effect. Obviously, income effects are a strong candidate, especially when parental deaths are associated with costs and income losses due to chronic illnesses. If households are credit constrained, then reduced incomes can result in lower investments in education. Aside from these direct wealth effects, orphanhood can be associated with an increased value of the child's time in home production (as a substitute for adult labor) which results in less schooling. There may be discrimination against orphans and favoritism towards biological children for double orphans or among single orphans who do not reside with their surviving parent (i.e. are fostered out). Beyond the financial consequences of adult deaths and the implications of a loss of parental involvement, children who become orphans may 
suffer trauma which, in turn, affects schooling and health outcomes. Children who lose a parent due to AIDS specifically may be additionally stigmatized relative to other causes of death.

The available evidence of the impact of orphanhood, some of which is discussed in the next section, typically relates to the impact of orphanhood from HIV/AIDS and other causes in the short-run, often by examining a sample of school-age children in cross-sectional survey data. A small number of studies use longitudinal data over short-run (perhaps 1-2 years) periods in which household coping strategies may successfully mitigate the impact. Studies of long-run impacts and outcomes are rare. Understanding short-run outcomes is important, but short-run effects may not ultimately translate into worse welfare outcomes in the long-run (that is, in adulthood). For instance, the socio-economic consequences of a parent's death may affect outcomes around the time of illness or during a period of funeral/mourning. However, as extended families foster in orphans, these outcomes may recover over time. $^{1}$

The next section reviews some of the existing empirical analysis. Section 3 discusses the data used in this study. Sections 4 and 5 present the empirical specifications and results. The final section concludes.

\section{Background}

The existing literature on the consequences of orphanhood tends to focus on education outcomes and use cross-sectional data, which may limit the robustness of the outcomes. The findings of these studies are mixed ${ }^{2}$ as are the findings of the few studies looking at other outcomes such as health. Few studies have also used panel data, which allows for extensive control of initial conditions.

Among the studies using large cross-sectional household survey data, several control for concurrent household characteristics to identify the impact of the loss of a parent on schooling. To the extent that orphans are found in relatively better-off households that also have higher demand for schooling, simple cross-sectional comparisons of enrollment rates between orphans and non-orphans may underestimate the true impact (for example, see Hargreaves and Glynn, 2002, and Ksoll, 2007). On the other hand, depending on mortality patterns, in some settings, an orphan's household may be poorer prior to death, thus over-estimating the impact of orphanhood.

Ainsworth and Filmer (2006) find considerable diversity in the orphan/non-orphan differential across countries and conclude that it is difficult to draw generalizations about the extent to which orphans

\footnotetext{
${ }^{1}$ See the studies cited in Golden (1994) regarding catch-up growth among stunted malnourished children.

2 Even estimates of the number of orphans is debated, with some research showing that the commonly-cited statistics from the UN may be seriously over-estimating the number of orphans (Bennell, 2005).
} 
are disadvantaged. ${ }^{3}$ Case et al. (2004) use cross-section data; using household fixed effects, they find that orphans are disadvantaged relative to other children within the same household. However, it is not clear that a household fixed-effects approach is satisfactory. If orphans are strategically placed in better-off households within the extended family, then the orphans in a household fixed-effects framework are compared to a non-random sample of non-orphan co-residents. It is then not shown that orphanhood reduces schooling, but rather that orphans are placed with better-off relatives. ${ }^{4}$ For instance, in their study of orphanhood in Zimbabwe, Nyamukapa and Gregson (2005) describe the system of childcare arrangements as traditionally based in part on both relatives' relationships with the orphan and their ability to assist. They further note that orphan care arrangements are increasingly being influenced by financial considerations.

Evidence of other outcomes for orphans beyond schooling is much more scant but here, too, the evidence is mixed (see for example Chatterji et al., 2005). In one of the few studies which is able to identify actual cause of death of parents, Crampin et al. (2003) examine health of children in Malawi on linked with information on the HIV/AIDS status of parents measured 10 years prior. ${ }^{5}$ They conclude that surviving children are not discriminated against as a result of parents having been ill or having died from HIV/AIDS. Another study of cross-sectional data finds that the health status of surviving orphans younger than 6 years is similar to their non-orphan counterparts in western Kenya (Lindblade et al., 2003).

The studies cited above use cross-sectional datasets which are limited to examining correlates of outcomes after a parental death, without controls for initial conditions, prior to the death of the parent(s). These studies only identify who is an orphan and not how recently a parent died or the status of the child prior to being orphaned. Depending on mortality patterns of adults, there could be omitted variables which bias results. Several recent studies utilize panel data available to address these concerns.

Using a panel survey from Tanzania covering 1991-94 (the baseline for this study, described in Section 3 below), Ainsworth et al. (2005) find that adult deaths are associated with delayed enrollment among younger children (7-10 years). Among orphans, younger maternal orphans are held back whereas

\footnotetext{
${ }^{3}$ Even conclusions from the same data sets can differ depending on how data from countries are combined. Bicego et al. (2003) combine Demographic and Health Survey household data across countries for West Africa and East Africa whereas Ainsworth and Filmer (2006) do not merge data sets across countries. In West Africa, Bicego et al. find evidence of a significant impact of among paternal orphans (6-14 years) and two-parent orphans (6-10 years). For East Africa, the findings are significant among maternal and two-parent orphans ages 11-14 years.

${ }^{4}$ Gertler et al. (2004) address problems of nonrandom selection into orphanhood (i.e. the death of a parent being correlated with other disadvantages but not caused by the event of losing a parent) using propensity score matching techniques. However, this matching is done between orphans and non-orphans based on characteristics of current residence which may itself be endogenous. Information on residence prior to orphanhood may be more appropriate but is not available to them.

${ }^{5}$ Of the 2,250 offspring identified from the 593 individuals for whom the HIV/AIDS status at baseline is known, Crampin et al. were able to trace 1,141. Of these, 761 offspring were alive and interviewed, 167 were alive but left the district and not traced, and 213 were deceased. It is unclear what the implications of this sample selection are on the measured impacts.
} 
other orphans are not found to be disadvantaged. Case and Ardington (2006) study schooling outcomes using a 2-3 year panel survey from South Africa. They find evidence of a causal effect of mother's deaths on children's education outcomes. Father's death, on the other hand, does not result in lower education, which instead is found to be indicative of the socio-economic conditions of the household prior to the death.

Ainsworth and Semali (2000) use the KHDS 1991-94 data (the baseline for this study) to present random and fixed child effects model estimates of adult death on children's height-for-age and weightfor-height. While random effects results show lower height for all maternal orphans and reduced height among paternal orphans in poor households, the fixed effects results are not significant possibly due to the small number of children who have any change in their orphan status in between the survey rounds (about 21 months from first to last interview). They find no association between the loss of a parent (regardless of being co-resident at the time) or recent adult death in the households and subsequent child weight-forheight. Overall, the authors conclude that policy interventions should target poor households in general, among which the households hardest hit by adult mortality are likely to be found. They identify population-wide policy interventions, like universal availability of oral rehydration salts at health facilities, measles vaccination and improved physical access to medical care as being most appropriate.

Using unique panel data from Kenya, Evans and Miguel (2007) study a large sample of nonorphans enrolled in grades 1-7 in 1998 and re-interviewed in 2002. They evaluate the impact of orphanhood transitions on schooling participation (measured as the fraction of visits in the school year in which the child was in school on the day of an unannounced check). Maternal deaths lead to lower participation after the death, as well as in the 1-2 years before the death. Paternal orphans did not have lower school participation. It is unclear how the measure of school participation translates into completed school years, but, presumably, it implies lower overall attainment. They also examine the direction of omitted variable bias and conclude that unobservable characteristics of orphans lead to underestimates of impact. Yamano and Jayne (2005) study the impact of prime-age adult deaths on schooling for 7-14 year olds using panel data from 2000 and 2002 which is similar, although not equivalent, to assessing the impact of orphanhood. They find much larger effects among children from poorer households. Girls suffer reduced schooling prior to the adult death while boys experience lower schooling after deaths.

While existing studies are varied in their methods and conclusions, several themes emerge. Panel data analyses show that omitted variable (pre-orphan characteristics) can bias results. Further, there may be considerable heterogeniety across different types of orphans, or in effects depending on the circumstances of different orphans, such as gender. For example, there is a higher likelihood that orphans who are fostered from a young age may be treated more like the children of the head, if foster children when fostered at young ages display similar bonding with foster parents as biological children. Likewise, 
conditional on age, outcomes may differ depending on whether a child was already enrolled when s/he become orphaned. Bhargava (2005) analyzes a sample of orphans and finds a positive relationship between enrollment prior to becoming an orphan and subsequent enrollment rates among orphans. Lastly, since these studies focus on samples of children, their findings may not reflect the consequences in adulthood of the loss of a parent as a child.

This paper contributes to the existing set of studies by presenting unique evidence of the extent to which orphanhood matters in the long-run for health and education outcomes. ${ }^{6}$ The data are from a region of Northwestern Tanzania deeply affected by the HIV/AIDS epidemic. We use a sample of nonorphaned children aged 6-15 surveyed in 1991-94, who were traced and re-interviewed as adults in 2004 . $^{7}$ A large proportion, 19 percent, lost one or both parents before the age of 15 in this period, allowing us to identify the permanent impact of orphanhood shocks. In the analysis, we can control for a wide range of child, parental, and household characteristics before the loss of the parent, as well as community fixed effects.

\section{Data}

The Kagera Region of Tanzania is located on the western shore of Lake Victoria, bordering Uganda to the north and Rwanda and Burundi to the west. The population (1.3 million in 1988, about 2 million in 2004) is overwhelmingly rural and primarily engaged in producing bananas and coffee in the northern districts and rain-fed annual crops (maize, sorghum, cotton) in the southern districts. The Kagera region is particularly insightful when studying the impact of HIV/AIDS. The first three cases of the disease were detected at Ndolage Hospital in $1983 .{ }^{8}$ Being one of the first regions in Africa to have been hit by the epidemic, it has a longer history of HIV/AIDS and therefore is one of the first places where one can attempt to analyze the intergenerational impact of the disease. Furthermore, Kagera had intensive socioeconomic data collection efforts early on in the epidemic, providing the necessary baseline data to perform such studies. In particular, this study uses baseline data from the Kagera Health and Development Survey (KHDS), a longitudinal socioeconomic survey conducted from September 1991 to

\footnotetext{
${ }^{6}$ This work also informs intergenerational models of the macroeconomic impact of AIDS which take into account the impact on human capital formation and its transmission between generations. Both Bell et al. (2006) and Corrigan et al. (2005) make assumptions about the magnitude of the impact of the death of a parent without reference to any empirical studies of this link.

${ }^{7}$ In Beegle et al. (2006), some basic analysis is presented on the impact of orphanhood on children in the sample. In that paper, the focus is also on a sample of children aged below 6 years of age in 1991-94. As these children have not yet reached adulthood by 2004, it is not possible to study the permanent impact of orphanhood, hence the focus on the older sample in this paper.

${ }^{8}$ Killewo et al. (1990), Killewo et al. (1993) and Kwesigabo et al. (2004) provide epidemiological data on HIV/AIDS prevalence and incidence in the region.
} 
January 1994 covering the entire Kagera region (see World Bank, 2004, and http://www.worldbank.org/lsms/).

In 2004, another round of data collection was completed (Beegle et al., 2006a). The goal of the KHDS 2004 was to re-interview the sample of about 6,200 respondents from the 1991-1994 survey. Considerable effort was made to track surviving respondents to their current location, be it in the same community (typically a village), a nearby community, within the region, or even outside the region or abroad. Excluding households in which all previous members are deceased (17 households with 31 people), the KHDS 2004 survey re-contacted 93\% of the baseline households (835 out of 895 households). The KHDS panel has an attrition rate that is much lower than that of other well-known panel surveys summarized in Alderman et al. (2001). Notably, most of the surveys in Alderman et al. cover considerably shorter time periods (2 - 5 years). Refusals in the KHDS were relatively uncommon; the main reason for not re-interviewing surviving panel respondents was failure to locate the respondent. ${ }^{9}$

The sample of households includes both orphaned and non-orphaned children. In the latter group, at baseline, there were 1,085 non-orphaned children aged 6-15 for which full baseline socio-economic and anthropometric information is available and who would be at least 19 years old by 2004 . Of these children, 822 (76 percent) were re-interviewed in 2004; 4 percent had died prior to 2004 and 20 percent were not located. Of these 822 tracked children, we have complete socio-economic and anthropometric data from baseline and follow-up for 718. Roughly half were traced outside of the baseline community, highlighting the importance of our tracking exercise to keep attrition rates low. In appendix 1, we present a brief analysis of the characteristics of the individuals lost in the sample. We show that despite less successful rates of re-interview for children with some observable characteristics, a number of corrections for attrition building on Becketti et al. (1998) and Fitzgerald et al. (1998) show that the results are unaffected by this attrition.

Even when parents are alive, children do not necessarily reside with them. As is the case in other Sub-Saharan countries, the rate of fostering of children is high in Tanzania. While fostering is associated with orphanhood, many non-orphaned children are not residing with one or both surviving parents. ${ }^{10}$ In

\footnotetext{
${ }^{9}$ It is interesting to note that the KHDS 2004 sample is remarkably similar to a random sample of households from Kagera, despite the fact that the baseline sample was not a simple random sample and given the (moderate) attrition since the baseline. The households in the KHDS 2004 had characteristics not significantly different as those found in the Core Welfare Indicators Questionnaire (CWIQ) survey in 2004 (including characteristics such as: household size, female headship, head's education, head's age, land holdings, livestock holdings, and dwelling characteristics). Among children under 18 years, 14\% in the KHDS 2004 are single or double-parent orphans and $63 \%$ of children were living with both parents. These numbers are strikingly close to results from the DHS 2003 . DHS 2003 survey found that $11 \%$ of the children under 18 years old in Kagera had lost one or both parents (a number equal to rate in the Tanzanian national sample). In the DHS, $60 \%$ of children in Kagera who were under 18 years of age live with both parents.

${ }^{10}$ Despite the high rate of fostering among both orphans and non-orphans, some studies use fostering as a proxy measure of orphanhood. For example, Deininger et al. (2003) draws conclusions regarding the consequences of
} 
the KHDS, one-parent orphans are significantly less likely to be residing with the surviving parent than children with both parents alive. In the baseline, 86 percent of non-orphans were residing with at least one parent. Among one-parent orphans, however, 67 percent were residing with the surviving parent.

Table 1 shows that out of our sample of 718 children, who at baseline had both parents alive, 133 lost either one or both parents before the age of 15 . The sample includes 52 people who lost their mother and 98 people who lost their father before the age of 15 . Only 17 people became double orphans before age 15 .

Table 2 shows that, starting from a sample of non-orphaned children aged 6-15 at baseline, those that subsequently lose a parent will, by adulthood, be on average $2 \mathrm{~cm}$ shorter and have 1 year less schooling than those who do not. Paternal and, especially, maternal orphanhood at childhood are statistically significant predictors of lower adult height, while only paternal orphanhood is statistically associated with lower education in adulthood. These correlations, however, do not control for other socioeconomic differences in these two groups of children, differences that could in part or in full explain the height and education gaps observed.

Before modeling the link between human capital indicators and orphanhood, we look at the household characteristics and socio-economic status during the baseline survey of those who became an orphan relative to their non-orphan counterparts, using simple significance tests of the differences in the means. As shown in table 3, those who had experienced the death of one or more parents before the age of 15 are, on average, less likely to live with either their mother or father at baseline. The heads in the households in which they were living during the baseline were older, less educated and more likely to be female. Further, they do not appear to be wealthier in terms of household consumption per capita or quality of flooring in the dwelling. The height of their mothers is also not significantly different. This would suggest that socio-economic differences determining selection into orphanhood are possibly not as strong as in some other studies. ${ }^{11}$ Nevertheless, these descriptive statistics suggest the need to carefully control for baseline characteristics of children, their parents, and the households in which children reside to make inference about the impact of subsequent orphanhood.

orphanhood using longitudinal household data from Uganda with information on child fostering. Yamano et al. (2005) conclude that these results will overestimate the negative impacts for orphans.

${ }^{11}$ In the panel data examined by Case and Ardington (2003), they found that paternal orphans had lower socioeconomic status. Their work concludes that the death of the father does not cause lower socio-economic outcomes but that poverty may have contributed to these deaths. 


\section{Modeling Health and Education Outcomes: Method and Results}

We are interested in assessing the impact of orphanhood shocks on long-run health and education outcomes for non-orphans aged 6 to 15 at baseline. The basic specification for health in this evaluation can be written as:

$$
H_{i 1}=\alpha+\beta X_{i o}+\gamma D_{i}+\delta H_{i o}+\varepsilon_{i 1}
$$

in which $H_{i 1}$ is health status in 2004, the vector $X_{i 0}$ is a set of individual, household and community control variables measured at baseline, which is the first KHDS interview of the child in 1991-94, and $H_{i 0}$ is the health status at baseline. The treatment of interest $D_{i}$ is the losing a parent between the baseline interview and the final interview in 2004. Thus, these deaths occur sometime between period $O$ (October 1991- January 1994) and period 1 (2004). Estimated using OLS, equation (1) is equivalent to a difference-in-differences specification with a set of controls, including initial health, and it can be straightforwardly shown, by subtracting $H_{i 0}$ from both sides of equation (1), that the parameter $\gamma$ offers the average treatment effect. Controlling for initial health status ensures that initial heterogeneity correlated to health endowments, health history and general child background as it affects changes in health status via $H_{i o}$, is captured. The basic specification for education is identical, using educational attainment at baseline and in 2004 instead of the health status variables.

The outcomes used in this study relate to investments which affect long-term economic prospects of children. We focus on height as the key long-term health measure, since it has been shown to affect wage-earning capacity as well as participation in the labor force for men and women (see Haddad and Bouis, 1991, and Thomas and Strauss, 1997). We model height as influenced by several factors, including the characteristics of the child (sex and age, via a full set of age dummies), genetic background of the family (using height at baseline for both the child and the mother), as well as the socio-economic environment in the household at baseline which is assumed to influence human development investment (including whether the child was living with the mother, whether the child was living with the father, years of education, sex and age of the household head and two indicators of wealth: cemented floor in dwelling and log per capita household consumption).

Educational attainment can be used as a proxy for human capital levels. We focus on the educational attainment in terms of the years of education completed, counting each grade completed as a year. We use a similar specification to the one above, whereby years of education in 2004 are determined by several factors, including child characteristics, years of education completed, and the same household characteristics as above. By controlling for years of education completed and whether enrolled in school at baseline, we further isolate the effect of orphanhood on education, net of its correlation with other unobserved background characteristics of these families influencing education. Finally, all our results 
control for community fixed effects at baseline, isolating the impact of orphanhood on health and education from factors such as access to schools and health services.

Baseline outcomes of height and schooling could be endogenous to their subsequent growth and thus to their 2004 levels. We therefore opt to instrument these baseline outcomes, using 2SLS. As instruments we use shocks that occurred prior to the baseline and which can reasonably be expected to affect baseline outcomes, but not subsequent growth (unless the effect is through baseline outcomes). Height and initial schooling at baseline is likely to be correlated with socio-economic shocks during childhood. We use both past rainfall and more recent shocks as instruments. In particular, as instruments we use the deviation in millimeters from normal rainfall patterns when the child was 2-3 years old, as events in early childhood have been shown to be a cause of stunting and low educational achievement (Glewwe et al., 2001). These are likely to be valid instruments as their effects will be visible throughout childhood (Martorell, 1999). Following Beegle et al. (2004), we also use the share of harvest lost in the year prior to the survey as an instrument.

These regressions are then repeated with various different specifications to explore and assert their robustness, including the OLS difference-in-differences estimator (i.e. without instruments for baseline outcomes) and the same regression without including baseline height or schooling, simply looking at 2004 attainments. As a final robustness check we balance treatment and comparison units in terms of the baseline characteristics that are likely to influence orphanhood. We trim our sample according to the parameters specified in Crump et. al. (2006), where the propensity score $s$ should be in the interval

$$
\left(0.5-\sqrt{0.25-\gamma^{-1}}, 0.5+\sqrt{0.25-\gamma^{-1}}\right)
$$

with $\gamma$ the solution to

$$
\gamma=2 E\left[\frac{1}{s(s-1)} \mid \frac{1}{s(1-s)}<\gamma\right]
$$

Depending on the specification, observations with propensity scores below 0.4-0.8 and above 0.92-0.96 were dropped. Following Hirano et al. (2003) and Hirano and Imbens (2001) we then present efficient estimators of the average treatment effect on the treated by running a weighted regression of the orphanhood dummy $D_{i}$ on the 2004 outcome variable $H_{i}$ as in (2).

$$
H_{i 1}=\alpha+\gamma D_{i}+\varepsilon_{i 1}
$$

Treatment observations are weighed at unity, while control observations get a weight of $s /(1-s)$. Propensity scores are predicted from a probit model that includes all covariates used in the OLS regressions described above (including village dummies). Note that this set-up only allows us to enter one treatment variable at a time. The coefficient $\gamma$ is the average treatment effect on the treated. 
Table 4 shows the results of the basic regressions, allowing for a separate effect of maternal and paternal orphanhood and with full controls for baseline and child characteristics and instrumented baseline outcomes. The reported coefficients are the 2SLS estimator of the average treatment effect of maternal and paternal mortality, with endogenous initial height/schooling. Full first and second stage results, as well as some IV diagnostics are given in appendix $2 .{ }^{12}$ To make the results between health and education fully comparable, we use effectively identical specifications and samples for both outcomes. Table 5 shows the results of a number alternative specifications of this model, as discussed above.

Based on table 4, the effect of maternal orphanhood on height amounts to just over 1 percent or $1.8 \mathrm{~cm}$ of height lost. As the average age at which children in the sample get orphaned is 11 years, this implies that we find evidence of shocks impacting growth in teen and pre-teen ages. This phenomenon, although to our knowledge never documented for developing countries, has been studied in developed countries, for example in research on anorexia (Davis et al., 1978, Pugliese et al., 1983, Modan-Moses et al., 2003). The results on education show an impact of maternal orphanhood of just over 1 year. The educational loss of maternal orphanhood from ages 6-15 is significant and substantive: it does not just delay education, but reduces it by one year by adulthood. This represents 33 percent of one standard deviation of years of education in this sample. Table 4 further shows that paternal orphanhood, while negatively correlated with final height and schooling in the bivariate statistics of table 2, does not appear to have a causal impact.

Table 5 repeats these results for health with different specifications. The size and significance of the impact of maternal death adult height and schooling remain robust to not instrumenting initial height and initial schooling (panel 1) and to dropping initial height and initial schooling (panel 2). Panel 3 presents an alternative estimator based on a trimmed sample and weights estimates average treatment effects through a weighted regression with unity weights for treatment observations and $s /(1-s)$ weights for controls, where $s$ is the estimated propensity score. Depending on the specification samples were trimmed off observation with propensity score estimates below 0.4-0.8 and above 0.92-0.96, following the criteria set out in Crump et al. (2006). Again we find no impact of paternal death and a large and significant impact of maternal death on adult height and schooling.

These regressions only control for the gender of the child using a dummy variable. Further analysis (not presented) showed that the impact of orphanhood had no gender dimension -- the impact was never significantly sex-dependent. The potential additive effect of losing both parents was also tested and found not to be significant. This result should be treated with caution, however, as there are only few

\footnotetext{
${ }^{12}$ The instruments are strongly significant in the first stage regression and not 'weak', provided we allow for a size distortion of the IV estimates of around 25 percent of the bias using the critical values of Stock and Yogo (2003).
} 
double orphans in the sample. Double-orphanhood also did not affect the magnitude of the effects of orphanhood episodes so it is not considered further.

Unpacking the results further, we explored whether there was any heterogeneity in the impact of orphanhood in other dimensions. For example, we investigated whether the impact on health and education differed with family wealth, by interacting the orphanhood variable with the baseline consumption expenditure variable. The interaction term was not significantly different from zero.

Finally, we investigated whether there was any impact of different living arrangements. In principle, understanding the impact of fostering and other living arrangements as a coping mechanisms after orphanhood is of considerable interest, not least for policy responses, but not easily investigated as the placement of orphans may well be correlated with unobservable child and household characteristics, affecting inference on the heterogeneity of the impact of orphanhood in the data. ${ }^{13}$ However, we can explore the consequences of living arrangements at the baseline, before orphanhood, by interacting the orphanhood shock with whether the child was living with the respective parent that subsequently died at the time of the baseline survey. As discussed in section 2, a substantial number of our sample of the nonorphaned children at baseline where not living with their mother or father in that period (table 3). While for height, we find no significantly different effect according to living arrangements, for education, we find that the entire impact of maternal death on schooling is confined to those children living with their mother at baseline; those fostered have no significantly negative schooling effect from orphanhood. ${ }^{14}$ It appears therefore that fostering can shelter children from the negative effects of orphanhood in the data. Still, placement issues may also trouble this result, for example, if only more able children are taken out of households with ill parents to continue their education, so caution is warranted.

\section{Interpreting the Findings}

One of the key problems in assessing the impact of shocks such as orphanhood is that unobservables correlated with orphanhood may bias the results: even after controlling for observables, orphanhood is not random. Finding that orphanhood is significant may not actually determine a causal impact, but may rather capture effects of unobservable covariates. For example, if particular attitudes towards health lead to parental illness and death as well as to poor health outcomes of the child, then orphanhood in itself is not the cause of lower height attainment in the child. An alternative narrative could

\footnotetext{
${ }^{13}$ For example, more able or healthier children may more easily be adopted by other families. Ksoll (2007), using a sub-sample of the KHDS data set explores the placement of double orphans based on a further survey of the extended family network.

${ }^{14}$ In this case, we also find some significant effect of paternal death for those living with their father at baseline. The effect is considerably smaller than for maternal death.
} 
also be that it is the illness of the parent that really causes the health or educational deprivation of the child, and not the actual death of the parent.

One avenue of investigating causality is to classify the sample of non-orphans used in the previous section by their future orphan status. That is, we know in later survey rounds which non-orphans in the sample became orphans by the second round (2004). We would expect that future orphan status would not be correlated with current outcomes unless (i) orphanhood captures some unobservable characteristics for which we are unable to control or (ii) morbidities associated with deaths affect outcomes before becoming an orphan. This approach follows Case and Ardington (2006) who make a causal interpretation of maternal orphanhood in a panel (2001 to 2003/04) by showing no effect of future orphan status on current schooling. Likewise, Evans and Miguel (2007) make note of the same issue in the context of censoring of the last round of their panel data since they include post-orphan variables which by definition are unknown for non-orphaned children in the final survey round.

Table 6 presents the regressions results of the correlates of height and years of education completed at the time of the baseline survey. The child and baseline control variables are identical to table 4 , including a control for initial community fixed effects. Future orphanhood is not correlated with baseline height or education, suggesting that unobservables correlated with health and education are not correlated with becoming an orphan in the future.

Finally, what do these losses in terms of health and education mean for the overall loss in living standards brought on by orphanhood? To quantify these consequences, ideally, we should estimate earnings functions to obtain the returns to height and education. However, we do not have income data within the data set. Instead, we can estimate returns using total consumption expenditure in 2004, providing a useful proxy for overall living standards, based on the sample studied in this paper, who are young adults in 2004. We first use a simple specification, consistent with the standard Mincerian earnings regression, in which consumption expenditure per capita is regressed on the logarithm of height and years of education, controlling for a full set of age dummies and sex. However, this is unlikely to measure correctly the marginal effect of height and education, as factors such as health and education endowments and family background, likely to be correlated with height and education, are not included. We therefore include a second specification, using all household and parental level baseline controls (including wealth variables, parental education and mother's height), and community fixed effects, i.e. a full set of controls as used in table 4.

Table 7 reports the coefficients of interest of these regressions, finding very strongly significant effects from both health and education in both specifications. When background controls are not included, the bias in estimated effects is in the direction expected, although small; returns are lower when controls are included. A one percent height gain adds 2.2 percent to consumption per capita, while an extra year of 
education adds 5.4 percent to consumption per capita for this sample of young adults. ${ }^{15}$ Based on our results in table 4 , this would imply an overall loss in consumption per capita of about 8.5 percent due to orphanhood.

\section{Conclusions}

This paper has provided unique and robust evidence on the long-term effects of the loss of a parent on children, based on a sample of children first interviewed in 1991-94 and re-interviewed as adults in 2004. Controlling for a wide range of household and child conditions before orphanhood and for community fixed effects we find evidence of persistent and causal impacts of becoming a maternal orphan before the age of 15. Paternal orphanhood, while correlated with lower final height and years of schooling was not found to have a causal link. The sample underlying this study is unique in that the project spent considerable resources tracing all individuals initially interviewed, even if they had started their own households or moved out of the village by 2004. Attrition rates would have doubled if respondents had not been tracked outside of the village.

Even with this quantification of the causal effects of orphanhood on socioeconomic outcomes of children, policy prescriptions from this work and other such studies remain elusive. Multiple potential policy responses exist. This paper cannot address whether, for example, one should offer ART to AIDSinfected women, scale up HIV/AIDS prevention campaigns or provide scholarships to maternal orphans In this sense, the findings here are interesting in general but perhaps more so when the context is considered. In parts of this region of Tanzania, substantial interventions for some households and villages have taken place. It is not possible to state from this study that the impact is at all affected in positive or negative sense by existing interventions. If anything, the impact exists despite any existing interventions and programs.

With these considerations in mind, in future work, the impact of specific programs and interventions will have to be explored further, as well as other long-term impacts of orphanhood and other shocks, such as to what extent orphanhood is the main source of deprivation among children or just one of

\footnotetext{
${ }^{15}$ To our knowledge, there are no comparable returns to health estimates for Tanzania. Recent careful estimates on the returns to education in the period 1993 to 2001, based on employees in manufacturing enterprises suggest a return for a cohort of workers below 30 years of age of about 9 percent per year (Söderbom et al. 2006). As our sample includes agriculture and other sectors, the fact that our estimated returns are lower should not come as a surprise. Nevertheless, it also implies that our estimate of the cost of orphanhood may well be an underestimate.
} 
many factors relevant for targeting the poor and vulnerable. Establishing the size of the long-term impact of orphanhood on children, as achieved in this paper, is nevertheless an essential first step. 
Table 1: Transitions in Orphan Status among Non-orphans 6-15 at Baseline

\begin{tabular}{lcc}
\hline & $\mathrm{N}$ & Percentage \\
\hline Both parents alive at age 15 & 585 & $81.4 \%$ \\
One parent died before age 15 & 133 & $18.5 \%$ \\
Mother died before age 15 & 52 & $7.2 \%$ \\
Father died before age 15 & 98 & $13.6 \%$ \\
Double orphan by age 15 & 17 & $2.3 \%$ \\
\hline
\end{tabular}

Mean age when orphaned among orphans $\quad 11.3$

Number of observations 718

Notes: Lost mother and lost father categories include double orphans, hence rows do not add up to $100 \%$. For double-orphans the younger age is taken to calculate mean age orphaned. 
Table 2: Average Adult Height and Schooling Attainment of Orphans and Non-orphans

\begin{tabular}{|c|c|c|c|c|c|}
\hline & $\begin{array}{l}\text { Mean final } \\
\text { height } \\
\text { non-orphans } \\
\text { (cm) }\end{array}$ & $\begin{array}{l}\text { Mean final } \\
\text { height } \\
\text { orphans } \\
\text { (cm) }\end{array}$ & $\begin{array}{c}\text { Difference in } \\
\text { mean final } \\
\text { height } \\
(\mathrm{cm})\end{array}$ & $\begin{array}{c}t \text {-stat of } \\
\text { difference }\end{array}$ & $\begin{array}{l}p \text {-value of } \\
\text { difference } \\
\text { (one-sided) }\end{array}$ \\
\hline Either parent died before age 15 & $\begin{array}{r}162.83 \\
(585)\end{array}$ & $\begin{array}{r}160.93 \\
(133)\end{array}$ & 1.90 & 2.47 & 0.007 \\
\hline Mother deceased before age 15 & $\begin{array}{r}162.65 \\
(666)\end{array}$ & $\begin{array}{r}160.30 \\
(52)\end{array}$ & 2.35 & 2.03 & 0.021 \\
\hline \multirow[t]{2}{*}{ Father deceased before age 15} & $\begin{array}{r}162.69 \\
(620)\end{array}$ & $\begin{array}{r}161.10 \\
(98)\end{array}$ & 1.59 & 1.83 & 0.034 \\
\hline & $\begin{array}{c}\text { Mean final } \\
\text { schooling } \\
\text { non-orphans } \\
\text { (years) }\end{array}$ & $\begin{array}{c}\text { Mean final } \\
\text { schooling } \\
\text { orphans } \\
\text { (years) } \\
\end{array}$ & $\begin{array}{c}\text { Difference in } \\
\text { mean final } \\
\text { schooling } \\
\text { (years) }\end{array}$ & $\begin{array}{c}t \text {-stat of } \\
\text { difference }\end{array}$ & $\begin{array}{l}p \text {-value of } \\
\text { difference } \\
\text { (one-sided) }\end{array}$ \\
\hline Either parent died before age 15 & $\begin{array}{r}6.24 \\
(585)\end{array}$ & $\begin{array}{r}5.44 \\
(133)\end{array}$ & 0.80 & 2.82 & 0.003 \\
\hline Mother deceased before age 15 & $\begin{array}{r}6.13 \\
(666)\end{array}$ & $\begin{array}{l}5.62 \\
(52)\end{array}$ & 0.52 & 1.21 & 0.113 \\
\hline Father deceased before age 15 & $\begin{array}{r}6.22 \\
(620)\end{array}$ & $\begin{array}{l}5.33 \\
(98)\end{array}$ & 0.89 & 2.77 & 0.003 \\
\hline
\end{tabular}


Table 3: Difference in Baseline Characteristics by Future Orphan Status

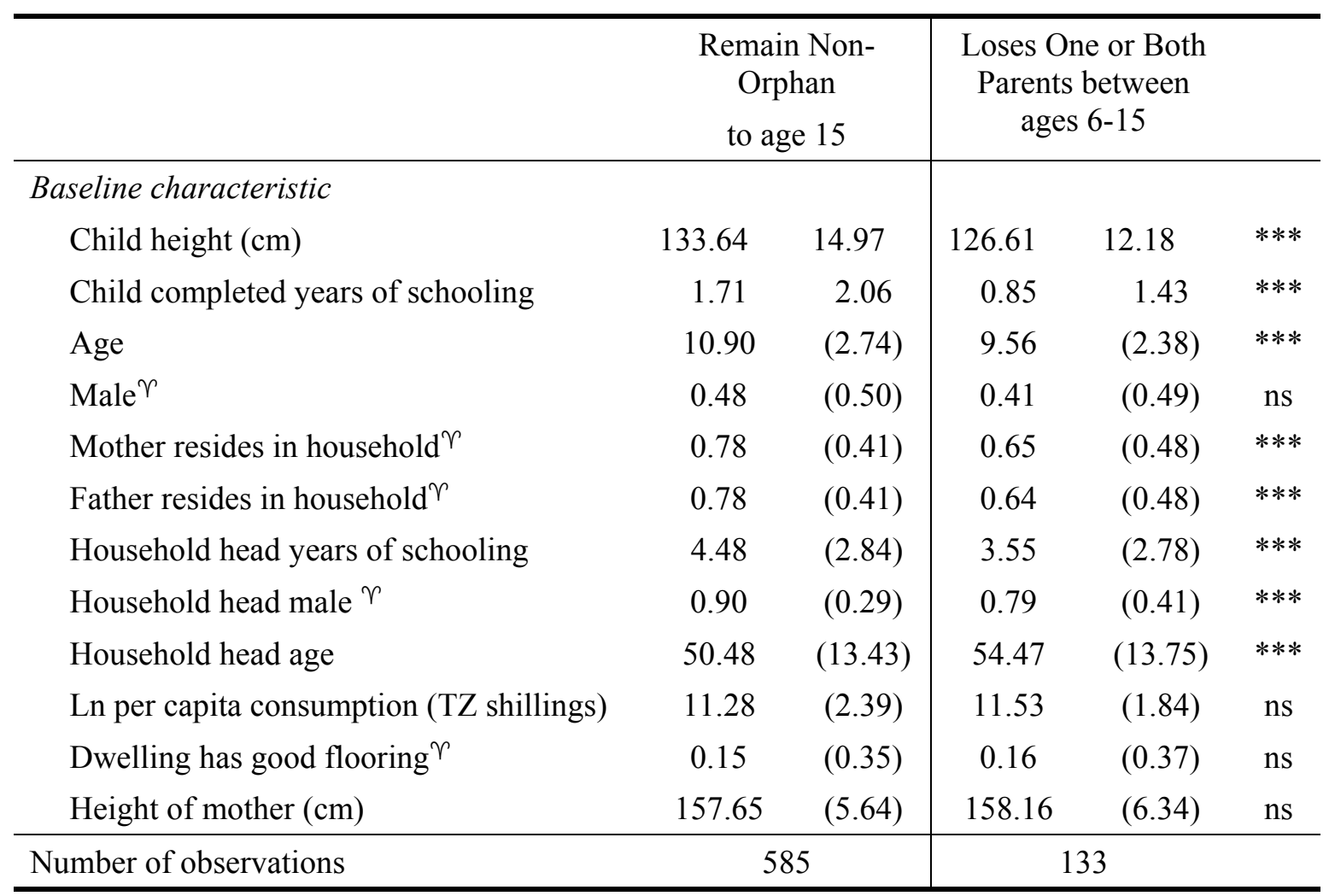

Notes: Standard deviations are in parentheses. ${ }^{\gamma}$ indicates binary $(0 / 1)$ variables. Level of significance is noted from a (two-sided) $t$-test for the difference between the two columns: * significant at $1 \%$, ** significant at 5\%,*** significant at $10 \%$, "ns" not significant at $10 \%$. 
Table 4: Determinants of Height and Years of Schooling in 2004

(1)

\begin{tabular}{|c|c|c|}
\hline Dependent Variable & Ln height & Years of Schooling \\
\hline \multirow[t]{2}{*}{ Mother died } & $-0.011 *$ & $-1.134 * *$ \\
\hline & $(0.006)$ & $(0.451)$ \\
\hline \multirow[t]{2}{*}{ Father died } & -0.0003 & -0.339 \\
\hline & $(0.004)$ & $(0.317)$ \\
\hline Number of observations & 718 & 718 \\
\hline \multicolumn{3}{|c|}{$\begin{array}{l}\text { Notes: 2SLS estimates with community fixed effects. Standard errors in } \\
\text { parentheses. * significant at } 10 \%, * * \text { significant at } 5 \%, * * * \text { significant at } 1 \% \text {. } \\
\text { Includes controls for child characteristics (sex and age dummies), baseline } \\
\text { characteristics (residing with mother and residing with father; household } \\
\text { consumption, flooring material, age, years of education and sex of the household } \\
\text { head). Regressions (1) includes the instrumented height of the child at baseline } \\
\text { and, when available, mother's height from the baseline data. Regression (2) } \\
\text { includes the instrumented number of years of education of the child at baseline. } \\
\text { Instruments are, respectively, share of harvest lost in year prior to baseline and } \\
\text { rainfall deviation during long rains at age } 2-3 \text {. F (Cragg-Donald) 'weak' } \\
\text { identification tests have the value of } 5.58 \text { and } 4.95 \text { respectively, suggesting an } \\
\text { approximate size distortion in the IV estimates of about } 25 \text { percent of the OLS } \\
\text { bias (and somewhat more for the schooling regression) (as in Stock and Yogo, } \\
2003 \text {, table 2). The first stage equation is exactly identified. }\end{array}$} \\
\hline
\end{tabular}


Table 5: Robustness Tests of Table 4 Results: Alternative Specifications

Dependent Variable

(1)

(2)

Ln height Years of schooling

PANEL 1: OLS Cluster FE without IVs for initial schooling/health

Mother died $-0.010^{*}$

$-1.019 * * *$

(0.006)

$(0.389)$

Father died

0.000

$-0.386$

Number of treatment observations mother died

(0.004)

(0.300)

Number of treatment observations father died

52

52

Number of observations

98

98

PANEL 2: Cluster FE without initial schooling/health

Mother died

$\begin{array}{cc}-0.013^{* *} & -0.866^{* *} \\ (0.006) & (0.408)\end{array}$

Father died

$-0.001$

$-0.450$

$(0.005)$

$(0.315)$

Number of treatment observations mother died

52

52

Number of treatment observations father died

98

98

Number of observations

718

718

PANEL 3: Propensity Score Weighted Regression

Mother died $-0.017 * *$ $-1.142 * *$

$(0.009)$

Number of treatment observations

46 46

Number of observations 383 383

Father died $-0.008$

Number of treatment observations

Number of observations

86 86

Notes: Regressions in Panel 1-2 are specified as those of table 4, but with different specifications as documented in the panel's heading. Following Hirano et al. (2003), Panel 3 estimates average treatment effects through a weighted regression with unity weights for treatment observations and $s /(1-s)$ weights for controls, where $s$ is the estimated propensity score. Samples were trimmed following the criteria set out in Crump et al. (2006). Depending on the specification, observations with propensity scores below $0.4-0.8$ and above $0.92-0.96$ were dropped. Standard errors in parentheses. * significant at 10\%, ${ }^{* *}$ significant at $5 \%, * * *$ significant at $1 \%$. 
Table 6: Predicting Baseline Outcomes by Future Orphan Transitions

\begin{tabular}{lcc}
\hline & \multicolumn{2}{c}{ Dependent Variable } \\
& $\begin{array}{c}\text { Ln height at } \\
\text { baseline }\end{array}$ & $\begin{array}{c}\text { Years of schooling } \\
\text { at baseline }\end{array}$ \\
\hline Mother died & -0.006 & -0.099 \\
& $(0.008)$ & $(0.146)$ \\
Father died & -0.011 & 0.237 \\
\hline Number of observations & 718 & $(0.190)$ \\
\hline
\end{tabular}

Notes: OLS estimates with community fixed effects. Standard errors in parentheses. See notes to table 4.

\section{Table 7: Effect of Attained Schooling and Height on 2004 Consumption Per Capita}

\begin{tabular}{|c|c|c|}
\hline & \multicolumn{2}{|c|}{ Dependent Variable } \\
\hline & (1) & (2) \\
\hline & $\begin{array}{c}\text { Ln per capita } \\
\text { consumption } 2004\end{array}$ & $\begin{array}{c}\text { Ln per capita } \\
\text { consumption } 2004\end{array}$ \\
\hline & OLS & OLS with controls \\
\hline \multirow[t]{2}{*}{ Ln height 2004} & $2.399 * * *$ & $2.154 * *$ \\
\hline & $(0.662)$ & $(0.701)$ \\
\hline \multirow[t]{2}{*}{ Years of schooling 2004} & $0.078 * * *$ & $0.055 * * *$ \\
\hline & $(0.009)$ & $(0.010)$ \\
\hline Number of observations & 681 & 681 \\
\hline
\end{tabular}




\section{Appendix 1: Attrition in the KHDS survey}

In comparison with most longitudinal surveys, attrition in the KHDS is low; among baseline households, in 93 percent of households at least one baseline household member was reinteriewed in 2004. Among all surviving members of the baseline households, about 82 percent were reinteriewed in 2004. Among the target group in this paper, non-orphaned children of age 6-15 at baseline, attrition is slightly higher; 79 percent of the non-deceased children were reinteriewed in 2004. About half these were found back due to the extensive efforts to locate people how had physically moved to a new village. Any area (town, district or even neighboring country) to which children were reported to have moved was visited by a specific search and survey team to minimize non-random attrition. Despite these efforts and the low attrition rate, it is still possible that attrition may cause problems for our analysis. ${ }^{1}$ Attrition linked to unobservables cannot be addressed in this data set; as in Fitzgerald et al. (1998), we focus on attrition linked to observables.

These results suggest some potential problem of non-random attrition. While it is plausible that the descriptive statistics in this paper are affected to some extent, our focus is on the regression analysis aiming to establish causal links between orphanhood and outcomes at adulthood. First, any attrition linked to particular clusters is not likely to be problematic, as all the regression analysis controls for cluster fixed effects so that all effects are identified using within- cluster variation, while for every cluster in the sample at least 55 percent of the cluster sample was found back. Secondly, we used the approach suggested by Fitzgerald et al. (1998), and use the inverse of the probabilities of an individual to remain in the sample by 2004, as predicted by baseline characteristics and with the probabilities normalised to keep the sample size at 718 observations. These probabilities are based on the same specification as in table A.1 but using the logit model with cluster dummies rather than the conditional fixed effects model, as otherwise some sampled individuals could not be assigned a probability of remaining in the sample. The results of the specification equivalent to table 4 in the main text are given below, and (possibly, not 
surprisingly given the discussion in Deaton, 1997), the results are virtually identical to table 4 in the main text. Thirdly, it could be that there are behavioral differences for those groups we specifically had difficulty tracking. In line with Becketti et al. (1998), a simple approach to explore this is to interact the variables related to orphanhood with those observable traits correlated with attrition. Interaction terms related to consumption per capita, and whether the child was living with the father at baseline were found to be insignificant, lending further credence to the conclusion that attrition is not affecting our results.

Table A.1: Correlates of Attrition (Dependent Variable = if child dropped out of sample) Conditional fixed effects logit model

\begin{tabular}{ll}
\hline Male & -0.067 \\
& $(0.169)$ \\
Mother resides in household & -0.015 \\
& $(0.215)$ \\
Father resides in household & $-0.674 * *$ \\
& $(0.238)$ \\
Height in centimeters & 0.010 \\
& $(0.012)$ \\
Attending school now? & 0.033 \\
& $(0.210)$ \\
Household head male & -0.191 \\
Household head age & $(0.291)$ \\
& -0.010 \\
Household head years education & $(0.007)$ \\
& 0.047 \\
Ln per capita consumption & $(0.036)$ \\
(TZ shillings) & $0.512^{* *}$ \\
Dwelling has good flooring & $(0.207)$ \\
& -0.161 \\
Number of observations & $(0.257)$ \\
\hline were dropped since the fixed effects logit is only identified \\
for cluster in which there was some attrition. \\
\hline
\end{tabular}

\footnotetext{
${ }^{1}$ As reported, 4 percent of the children died before the 2004 round, but the small absolute number involved makes is hardly sensible to conduct detailed analysis.
} 
Table A.2: Determinants of Height and Years of Schooling in 2004

\begin{tabular}{|c|c|c|}
\hline & \multicolumn{2}{|c|}{ Dependent Variable } \\
\hline & (1) & (2) \\
\hline & Ln height & Years of Schooling \\
\hline \multirow[t]{2}{*}{ Mother died } & $-0.012 *$ & $-1.085^{* *}$ \\
\hline & $(0.006)$ & $(0.435)$ \\
\hline \multirow[t]{2}{*}{ Father died } & -0.0002 & -0.185 \\
\hline & $(0.0002)$ & $(0.306)$ \\
\hline Number of observations & 718 & 718 \\
\hline \multicolumn{3}{|c|}{$\begin{array}{l}\text { Notes: Weighted 2SLS estimates with community and age fixed } \\
\text { effects. Weights are the inverse of the predicted probability of } \\
\text { inclusion in sample. Logit model predictions with specification as in } \\
\text { table A.1. Standard errors in parentheses. * significant at } 10 \% \text {, ** } \\
\text { significant at } 5 \%, * * * \text { significant at } 1 \% \text {. All other independent } \\
\text { variables as in table } 4 \text { (coefficients not reported). }\end{array}$} \\
\hline
\end{tabular}




\section{Appendix 2: Table 4 full regression results}

\section{Table A2.1: First Stage Regression Results (Table 4)}

\begin{tabular}{|c|c|c|}
\hline & \multicolumn{2}{|c|}{ Dependent Variable } \\
\hline & (1) & (2) \\
\hline & $\begin{array}{l}\text { Ln Height } \\
\text { at baseline }\end{array}$ & $\begin{array}{c}\text { Years of schooling } \\
\text { at baseline }\end{array}$ \\
\hline Share of farm harvest lost prior to baseline & $\begin{array}{l}-0.025^{* *} \\
(0.010)\end{array}$ & \\
\hline \multirow[t]{2}{*}{$\begin{array}{l}\text { Deviation of long rains when child was 2-3 } \\
\text { years old }\end{array}$} & & $0.001 * *$ \\
\hline & & $(0.000)$ \\
\hline \multirow[t]{2}{*}{7 years old } & $0.024 *$ & -0.063 \\
\hline & $(0.013)$ & $(0.240)$ \\
\hline \multirow[t]{2}{*}{8 years old } & $0.082 * * *$ & 0.115 \\
\hline & $(0.013)$ & $(0.240)$ \\
\hline \multirow[t]{2}{*}{9 years old } & $0.123 * * *$ & 0.138 \\
\hline & $(0.014)$ & $(0.256)$ \\
\hline \multirow[t]{2}{*}{10 years old } & $0.143 * * *$ & $0.492 * *$ \\
\hline & $(0.014)$ & $(0.245)$ \\
\hline \multirow[t]{2}{*}{11 years old } & $0.176^{* * *}$ & $1.139 * * *$ \\
\hline & $(0.014)$ & $(0.244)$ \\
\hline \multirow[t]{2}{*}{12 years old } & $0.224 * * *$ & $2.141 * * *$ \\
\hline & $(0.013)$ & $(0.232)$ \\
\hline \multirow[t]{2}{*}{13 years old } & $0.253 * * *$ & $2.793 * * *$ \\
\hline & $(0.014)$ & $(0.252)$ \\
\hline \multirow[t]{2}{*}{14 years old } & $0.277 * * *$ & $3.820 * * *$ \\
\hline & $(0.014)$ & $(0.242)$ \\
\hline \multirow[t]{2}{*}{15 years old } & $0.310 * * *$ & $4.503 * * *$ \\
\hline & $(0.014)$ & $(0.255)$ \\
\hline \multirow[t]{2}{*}{ Male } & -0.007 & -0.106 \\
\hline & $(0.005)$ & $(0.094)$ \\
\hline \multirow[t]{2}{*}{ Household head years education } & 0.001 & $0.044 * *$ \\
\hline & $(0.001)$ & $(0.021)$ \\
\hline \multirow[t]{2}{*}{ Household head male } & 0.007 & -0.297 \\
\hline & $(0.011)$ & $(0.195)$ \\
\hline \multirow[t]{2}{*}{ Household head age } & 0.000 & $0.008 *$ \\
\hline & $(0.000)$ & $(0.004)$ \\
\hline \multirow[t]{2}{*}{ Ln per capita consumption ( $\mathrm{TZ}$ shillings) } & 0.006 & $0.367 * * *$ \\
\hline & $(0.007)$ & $(0.116)$ \\
\hline Ln per capita consumption missing & 0.072 & $4.409 * * *$ \\
\hline
\end{tabular}




\begin{tabular}{lcc}
\hline & \multicolumn{2}{c}{ Dependent Variable } \\
& $(1)$ & $(2)$ \\
& $\begin{array}{c}\text { Ln Height } \\
\text { at baseline }\end{array}$ & $\begin{array}{c}\text { Years of schooling } \\
\text { at baseline }\end{array}$ \\
\hline \multirow{2}{*}{ Dwelling has good flooring } & $(0.079)$ & $(1.409)$ \\
& $0.016^{*}$ & 0.261 \\
Height of mother & $(0.009)$ & $(0.163)$ \\
Height of mother missing & $0.002^{* * *}$ & 0.010 \\
& $(0.001)$ & $(0.010)$ \\
Mother resides in household & $0.261^{* * *}$ & 1.279 \\
Father resides in household & $(0.089)$ & $(1.580)$ \\
Mother deceased before child is 15 years old & 0.007 & 0.127 \\
Father deceased before child is 15 years old & $(0.015)$ & $(0.260)$ \\
Constant & -0.011 & 0.106 \\
& $(0.009)$ & $(0.157)$ \\
Number of observations & -0.010 & 0.238 \\
Test of Excluded Instruments $F$-Value & $(0.011)$ & $(0.189)$ \\
Test of Excluded Instruments $p$-value & -0.006 & -0.096 \\
\hline
\end{tabular}


Table A2.2: Second Stage Regression Results (Table 4)

\begin{tabular}{|c|c|c|}
\hline & \multicolumn{2}{|c|}{ Dependent Variable } \\
\hline & (1) & $(2)$ \\
\hline & $\begin{array}{l}\text { Ln Height } \\
\text { in } 2004\end{array}$ & $\begin{array}{l}\text { Years of schooling } \\
\text { in } 2004\end{array}$ \\
\hline \multirow[t]{2}{*}{ Ln height at baseline } & 0.164 & \\
\hline & $(0.217)$ & \\
\hline \multirow[t]{2}{*}{ Years of school at baseline } & & 1.130 \\
\hline & & $(0.933)$ \\
\hline \multirow[t]{2}{*}{ Mother deceased before child is 15 years old } & $-0.011 *$ & $-1.134 * *$ \\
\hline & $(0.006)$ & $(0.451)$ \\
\hline \multirow[t]{2}{*}{ Father deceased before child is 15 years old } & -0.000 & -0.339 \\
\hline & $(0.004)$ & $(0.317)$ \\
\hline \multirow[t]{2}{*}{6 years old } & & 4.544 \\
\hline & & $(4.300)$ \\
\hline \multirow[t]{2}{*}{7 years old } & -0.013 & 4.720 \\
\hline & $(0.009)$ & $(4.347)$ \\
\hline \multirow[t]{2}{*}{8 years old } & -0.019 & 4.501 \\
\hline & $(0.019)$ & $(4.132)$ \\
\hline \multirow[t]{2}{*}{9 years old } & -0.024 & 4.211 \\
\hline & $(0.028)$ & $(4.032)$ \\
\hline \multirow[t]{2}{*}{10 years old } & -0.023 & 4.217 \\
\hline & $(0.032)$ & $(3.788)$ \\
\hline \multirow[t]{2}{*}{11 years old } & -0.033 & 2.571 \\
\hline & $(0.039)$ & $(3.255)$ \\
\hline \multirow[t]{2}{*}{12 years old } & -0.032 & 1.766 \\
\hline & $(0.049)$ & $(2.340)$ \\
\hline \multirow[t]{2}{*}{13 years old } & -0.032 & 1.487 \\
\hline & $(0.055)$ & $(1.680)$ \\
\hline \multirow[t]{2}{*}{14 years old } & -0.047 & 0.379 \\
\hline & $(0.060)$ & $(0.830)$ \\
\hline \multirow[t]{2}{*}{15 years old } & -0.045 & \\
\hline & $(0.068)$ & \\
\hline \multirow[t]{2}{*}{ Male } & $0.057 * * *$ & $0.566 * *$ \\
\hline & $(0.003)$ & $(0.223)$ \\
\hline \multirow[t]{2}{*}{ Household head years education } & -0.000 & $0.149 * *$ \\
\hline & $(0.001)$ & $(0.059)$ \\
\hline \multirow[t]{2}{*}{ Household head male } & -0.000 & -0.257 \\
\hline & $(0.006)$ & $(0.486)$ \\
\hline \multirow[t]{2}{*}{ Household head age } & -0.000 & 0.009 \\
\hline & $(0.000)$ & $(0.011)$ \\
\hline
\end{tabular}




\begin{tabular}{lcc}
\hline & \multicolumn{2}{c}{ Dependent Variable } \\
& $(1)$ & $(2)$ \\
& Ln Height & Years of schooling \\
Ln per capita consumption (TZ shillings) & -0.006 & 0.456 \\
& $(0.004)$ & $(0.412)$ \\
Ln per capita consumption missing & -0.055 & 5.401 \\
& $(0.043)$ & $(4.968)$ \\
Dwelling has good flooring & $0.010^{*}$ & $1.316^{* * *}$ \\
& $(0.006)$ & $(0.432)$ \\
Height of mother & $0.002^{* * *}$ & -0.016 \\
& $(0.000)$ & $(0.022)$ \\
Height of mother missing & $0.330^{* * *}$ & -3.857 \\
Mother resides in household & $(0.072)$ & $(3.425)$ \\
& -0.002 & -0.780 \\
Father resides in household & $(0.008)$ & $(0.556)$ \\
& -0.003 & -0.540 \\
Number of observations & $(0.005)$ & $(0.343)$ \\
\hline
\end{tabular}




\section{References}

Ainsworth, Martha, Kathleen Beegle, and Godlike Koda. 2005. "The Impact of Adult Mortality and Parental Deaths on Schooling in Northwestern Tanzania." Journal of Development Studies 41(3): 412439.

Ainsworth, Martha, and Deon Filmer. 2006. "Inequalities in Children's Schooling: AIDS, Orphanhood, Poverty, and Gender." World Development 34(6): 1099-1128.

Ainsworth, Martha and Innocent Semali. 2000. "The Impact of Adult Deaths on Children's Health in Northwestern Tanzania" Policy Research Working Paper 2266, Development Research Group. The World Bank: Washington DC.

Alderman, Harold, Jere R. Berman, Hans-Peter Kohler, John Maluccio, and Susan Cotts Watkins. 2001. "Attrition in Longitudinal Household Survey Data: Some Tests for Three Developing-Country Samples." Demographic Research 5(4).

Becketti, S., W.Gould, L. Lillard and F.Welch. 1988. "The Panel Study of Income Dynamics after Fourteen Years: An Evaluation." Journal of Labor Economics 6: 472-492.

Beegle, Kathleen, Joachim De Weerdt, and Stefan Dercon. 2006. "Orphanhood and the Long-Run Impact on Children”, American Journal of Agricultural Economics, 88 (5): 1266-72

Beegle, Kathleen, Joachim De Weerdt, and Stefan Dercon. 2006. "Kagera Health and Development Survey (KHDS), 2004, Basic Information Document." mimeo.

Beegle, Kathleen, Rajeev Deheija and Roberta Gatti. 2006. "Child Labor and Agricultural Shocks," Journal of Development Economics 81(1): 80-96.

Bell, Clive, Shanta Devarajan and Hans Gersbach. 2006. "The Long-run Economic Costs of AIDS: With an Application to South Africa." The World Bank Economic Review 20(1):55-89.

Bennell, Paul. 2005. "The Impact of the AIDS Epidemic on the Schooling of Orphans and Other Directly Affected Children in Sub-Saharan Africa." Journal of Development Studies 41(3): 467-488.

Bhargava, Alok. 2005. "AIDS Epidemic and the Psychological Well-being and School Participation of Ethiopian Orphans.” Psychology, Health and Medicine 10(3): 263-275.

Bicego, George, Shea Rutstein, and Kiersten Johnson. 2003. "Dimensions of the Emerging Orphan Crisis in Sub-Saharan Africa." Social Science and Medicine 56: 1235-1247.

Case, Anne and Cally Ardington. 2006. "The Impact of Parental Death on School Outcomes: Longitudinal Evidence from South Africa.” Demography 43(3): 402-420.

Case, Anne, Christina Paxson and Joseph Ableidinger. 2004. "Orphans in Africa: Parental Death, Poverty and School Enrollment." Demography 41(3): 483-508.

Chatterji, Minki, Leanne Dougherty, Tom Ventimiglia, Yvonne Mulenga, Andrew Jones, Antoinette Mukaneza, Nancy Murray, Kathy Buek, William Winfrey, and Joseph Amon. 2005. "The Well-Being of Children Affected by HIV/AIDS in Lusaka, Zambia, and Gitarama Province, Rwanda: Findings from a 
Study.” Community REACH Working Paper No. 2. Washington, DC: Community REACH Program, Pact.

Corrigan, Paul, Gerhard Glomm, and Fabio Mendez. 2005. "AIDS Crisis and Growth.” Journal of Development Economics 77(1): 107-124

Crampin Amelia, Sian Floyd, Judith Glynn, Nyovani Madise, Andrew Nyondo, Masiya Khondowe, Chance Njoka, Huxley Kanyongoloka, Bagrey Ngwira, Basia Zaba, and Paul Fine. 2003. "The Long-term Impact of HIV and Orphanhood on the Mortality and Physical Well-being of Children in Rural Malawi." AIDS 17(3): 389-97.

Crump, Richard, Joseph Holtz, Guido Imbens, and Oscar Mitnik. 2006. "Moving the Goalposts: Addressing Limited Overlap in Estimation of Average Treatment effects by Changing the Estimand." mimeo, UC Berkeley.

Davis, R., J. Apley, G. Fill, C. Grimaldi. 1978. "Diet and Retarded Growth.” British Medical Journal 1: 539-542.

Deaton, Angus. 1997. The Analysis of Household Surveys. Baltimore, Md., U.S.A.: Johns Hopkins University Press.

Deininger, Klaus, Marito Garcia, and K. Subbarao. 2003. "AIDS-Induced Orphanhood as a Systemic Shock: Magnitude, Impact, and Program Interventions in Africa.” World Development 31(7): 1201-1220.

Evans, David and Edward Miguel. 2007. "Orphans and Schooling in Africa: A Longitudinal Analysis." Demography 44(1): 35-57.

Fitzgerald, John, Peter Gottschalk and Robert Moffitt (1998). “An Analysis of Sample Attrition in Panel Data." Journal of Human Resources 33 (2): 251-299.

Gertler, Paul, David Levine, and Minnie Ames. 2004. "Schooling and Parental Death." The Review of Economics and Statistics 86(1): 211-225.

Glewwe, Paul, Hanan Jacoby, and Elizabeth King, 2001. "Early Childhood Nutrition and Academic Achievement: a Longitudinal Analysis." Journal of Public Economics 81(3): 345-368

Golden, M.H.N. 1994. “Is Complete Catch-up Possible for Stunted Malnourished Children?” European Journal of Clinical Nutrition 48 Suppl 1:S58-70.

Haddad, Lawrence and Howard Bouis. 1991. "The Impact of Nutritional Status on Agricultural Productivity: Wage Evidence from the Philippines." Oxford Bulletin of Economics and Statistics 53: 4568.

Hargreaves, James R., and Judith R. Glynn. 2002. "Educational Attainment and HIV-1 Infection in Developing Countries: A Systematic Review." Tropical Medicine and International Health 7(6): 489498.

Hirano Keisuke, Guido Imbens, and Geert Ridder, 2003. "Efficient Estimation of Average Treatment Effects Using the Estimated Propensity Score.” Econometrica 71(4): 1161-1189 
Hirano Keisuke and Guido Imbens. 2001. "Estimation of Causal Effects using Propensity Score Weighting: An application to Data on Right Heart Catheterization." Health Services \& Outcomes Research and Methodology 2: 259-278.

Jacoby, Hanan and Emmanuel Skoufias. 1997. "Risk, Financial Markets and Human Capital in a Developing Country." Review of Economic Studies 64: 311-336

Killewo, J. Z. J., Nyamuryekunge, K., Sandstrom, A., Bredberg-Raden, U., Wall, S., Mhalu, F., \& Biberfeld, G. 1990. "Prevalence of HIV-1 Infection in the Kagera Region of Tanzania: A Populationbased Study." Acquired Immune Deficiency Syndrome 4: 1081-1085.

Killewo, J. Z. J., Sandstrom, A., Bredberg-Raden, U., Mhalu, F., Biberfeld, G., \& Wall, S. 1993. "Incidence of HIV-1 Infection Among Adults in the Kagera Region of Tanzania." International Journal of Epidemiology 22(3): 528-536.

Ksoll, Christopher. 2007. "Family Networks and Orphan Caretaking in Tanzania." January, Yale University, mimeo.

Kwesigabo G., J. Killewo, W. Urassa, J. Lugalla, M. Emmelin, A. Mutembei, F. Mhalu, G. Biberfeld, S. Wall, and A. Sandstrom. 2005. "HIV-1 Infection Prevalence and Incidence Trends in Areas of Contrasting Levels of Infection in the Kagera Region, Tanzania, 1987-2000." Journal of Acquired Immune Deficiency Syndrome 40(5): 585-91.

Lindblade, Kim, Frank Odhiambo, Daniel Rosen, and Kevin DeCock. 2003. "Health and Nutritional Status of Orphans $<6$ Years Old Cared for by Relatives in Western Kenya." Tropical Medicine and International Health 8(1):67-72.

Martorell, R. 1999. "The Nature of Child Malnutrition and its Long-term Implications." Food and Nutrition 125 (Suppl): 1127S-1138S.

Modan-Moses, D., A. Yaroslavsky, I. Novikov, S. Segev, A. Toledano, E. Miterany and D. Stein. 2003. "Stunting of Growth as a Major Feature of Anorexia Nervosa in Male Adolescents." Pediatrics 111(2): 270-276.

Nyamukapa, Constance and Simon Gregson. 2005. "Extended Family's and Women's Roles in Safeguarding Orphans' Education in AIDS-afflicted Rural Zimbabwe." Social Science and Medicine 60: 2155-2167.

Pugliese, M., F. Lifshitz, G. Grad, P. Fort and M. Mark-Katz. 1983. "Fear of Obesity. A Cause of Short Stature and Delayed Puberty." The New England Journal of Medicine 309: 513-518.

Söderbom, M., F.Teal, A.Wambugu and G. Kahyarara (2006). "The Dynamics of Returns to Education in Kenyan and Tanzania Manufacturing." Oxford Bulletin of Economics and Statistics 68(3): 261-288.

Stock, J. and M. Yogo. 2003. "Testing for Weak Instruments in Linear IV Regression.” mimoe, Harvard University.

Thomas, Duncan and John Strauss. 1997. "Health and Wages: Evidence on Men and Women in Urban Brazil.” Journal of Econometrics 77-159-185. 
Yamano, Takashi and Thomas S. Jayne. 2005. "Working-Age Adult Mortality and Primary School Attendance in Rural Kenya." Economic Development and Cultural Change 53: 619-653.

Yamano, Takashi, Yasuharu Shimamura, and Dick Sserunkuuma. 2006. "Living Arrangements and Schooling of Orphaned Children and Adolescents in Uganda." Economic Development and Cultural Change 54 (4): 833-856.

World Bank. 2004. "User's Guide to the Kagera Health and Development Survey Datasets." mimeo. 